\title{
FUNÇÃO E IMAGEM CORPORAL:
}

\section{UMA ANÁLISE A PARTIR DO DISCURSO DE MULHERES SUBMETIDAS À CIRURGIA BARIÁTRICA*}

\author{
MS. MARCELA RODRIGUES DE CASTRO \\ Mestre em Educação Física pela Universidade Federal de Juiz de Fora (UFJF), \\ Pesquisadora do Laboratório de Estudos do Corpo (labesc) e Professora da \\ Rede Pública Municipal de Ensino de Juiz de Fora (Minas Gerais - Brasil) \\ e-mail: marcelarodriguescastro@hotmail.com
}

MS. RENATA SILVA DE CARVALHO

Mestre em Psicologia pela Universidade Federal de Juiz de Fora (UFJF), Pesquisadora do Laboratório de Estudos do Corpo (LABESC) e Professora da

Faculdade Estácio de Sá unidade Juiz de Fora (Minas Gerais - Brasil) e-mail: resilvajf@gmail.com

\section{MS. VANESSA NOLASCO FERREIRA}

Mestre em Psicologia pela Universidade Federal de Juiz de Fora (UFJF),

Pesquisadora do Laboratório de Estudos do Corpo (LABESC) e

Psicóloga Clínica (Minas Gerais - Brasil)

e-mail: vnolascoferreira@gmail.com

\section{DRA. MARIA ELISA CAPUTO FERREIRA}

Pós-Doutora e Doutora em Educação pela Universidade de São Paulo (USP), Professora Adjunta da Faculdade de Educação Física e Desportos da Universidade Federal de Juiz de Fora (UFJF),

Coordenadora do Laboratório de Estudos do Corpo (LABESC) (Minas Gerais - Brasil)

e-mail: caputoferreira@terra.com.br

* Este trabalho contou com o apoio financeiro da Fundação de Amparo à Pesquisa do Estado de Minas Gerais (FAPEMIG). 


\section{RESUMO}

OO presente artigo contempla um estudo sobre a correlação entre função e imagem corporal de mulheres submetidas à cirurgia bariátrica. Para tanto foi realizado um estudo qualitativo com base na metodologia de análise de conteúdo. Verificou-se, a partir das entrevistas com 20 pacientes, de um serviço especializado do Sistema Único de Saúde da cidade de Juiz de Fora / Minas Gerais, com idade média de 40 anos e que haviam realizado a cirurgia há 2,85 anos, tendo perda ponderal média de 74, I Kg, a intrínseca relação entre função e imagem corporal. Sendo essa expressa pelas mudanças após a perda de peso, as quais foram emergiram nas seguintes categorias: recuperação das funções corporais, da autonomia para reassumir antigos papéis sociais (como exercer funções como cuidar da casa, trabalhar ou mesmo encarar os relacionamentos de diferentes formas), além de se arriscarem em novas experiências. Assim, o grupo pesquisado passou a experimentar sentimentos de satisfação e de autoestima positiva, até então não vivenciados.

PALAVRAS-CHAVE: Obesidade; cirurgia bariátrica; imagem corporal.

\section{INTRODUÇÃO}

A obesidade é uma doença crônica não transmissível caracterizada pelo acúmulo de gordura que causa prejuízos à saúde, tanto física quanto psicológica, do indivíduo (NATIONAL INSTITUTES OF HEALTH CONSENSUS DEVELOPMENT CONFERENCE STATEMENTE, 1985).

Até o final do século $X \mathrm{IX}$, a obesidade esteve presente nos corpos de homens e mulheres como padrão de beleza e fertilidade, ou seja, relacionados a aspectos estéticos. Mas, a partir do século XXI, além de uma mudança para uma silhueta mais delineada, inicia-se uma preocupação com os aspectos patológicos relativos ao excesso de peso corporal. Essa preocupação se deve a uma tendência mundial ao aumento da massa corporal gorda, como apontam os dados da World Health Organization (WHO): prognósticos futuros indicam que, no ano de 20I5, aproximadamente 2,3 bilhões de adultos estarão acima do peso e 700 milhões serão obesos.

Diante desse panorama a maioria dos indivíduos obesos busca o emagrecimento a partir de tratamentos convencionais como dietas, atividade física e medicamentos. No entanto, vários pacientes não respondem a essas manobras, necessitando de uma intervenção mais radical, mais invasiva como a cirurgia bariátrica.

Realizada pela primeira vez por Kremem e Liner em 1954 (FARIAS, 2005, p. 35), a cirurgia bariatrica vem sendo considerada o tratamento mais eficaz na redução do peso nos casos de obesidade mórbida, bem como sua manutenção, tornando-se, dessa forma, um procedimento conhecido e realizado em todo 
mundo (SANTOS; BURGOS; SILVA, 2006, p. I87; SEGA; FANDIÑO, 2002, p. 70; ARASAKI; GRANDE; OLIVEIRA; ALVES, 2005, p. 288).

A gravidade do problema deu origem a um número significativo de pesquisas que demonstram que, além das comorbidades, a pessoa obesa é atingida também por distúrbios psicossociais (CARVALHO, 2005, p.36). Isso ocorre porque ela é alvo de discriminação e preconceito, que se inicia desde a infância. A sociedade, frequentemente, percebe o indivíduo obeso como uma pessoa indulgente em excesso e incapaz de se autocontrolar (POLLOCK; WILMORE; ROCHA, 1993, p.98). Dessa forma, a obesidade é vista como uma doença autoinfligida, podendo causar sofrimento, depressão e comportamentos de esquiva social (ADES; KERBAUY, 2002, p. 200).

Pesquisas de Segal e Fandiño (2002, p. 69) concluem que pessoas obesas cursam um menor número de anos escolares, têm menores chances de serem aceitas em escolas. $\bigcirc$ mesmo se dá em empregos mais concorridos, resultando em salários mais baixos. Além disso, têm menor chance de se envolverem em relacionamento afetivo estável.

Nesse sentido, os aspectos psicossociais relacionados à obesidade têm chamado atenção dos pesquisadores, incluindo a imagem corporal.

A imagem corporal é definida por Schilder (1994, p.35) como a figuração formada na mente a respeito do corpo, englobando aspectos fisiológicos, sociais, afetivos e libidinais. Além disso, Cash (1990, p. 70) acredita que ela se relaciona com a experiência psicológica do sujeito sobre sua aparência e o funcionamento do seu corpo. Segundo o autor, o descontentamento relacionado ao peso, que pode levar a uma imagem corporal negativa, é proveniente de uma ênfase cultural da magreza e do estigma social da obesidade.

De acordo com Almeida, Loureiro e Santos (2002, p. 284) a maioria dos estudos sobre imagem corporal direcionam-se para reflexão a respeito da insatisfação, depreciação e distorção da imagem corporal, sob influência de fatores socioculturais. Considerando o destaque dado por Cash ( 1990 p. 75) sobre a aparência e função como componentes importantes na construção da imagem corporal, pessoas com obesidade mórbida podem sofrer impacto negativo tanto pelo apelo ao corpo magro cultuado nos dias de hoje, como também experienciar prejuízos na funcionalidade de seu corpo.

A Classificação Internacional de Funcionalidade (CIF), descrita pela Organização Mundial de Saúde (OMS) (1993), considera funcionalidade corporal a interação dinâmica existente entre a condição de saúde e fatores ambientais e pessoais, de forma que uma intervenção num desses elementos pode modificar o todo.

Baseado nas ideias expostas, o presente estudo preocupou-se, em investigar se há uma relação entre as restrições e melhoras do funcionamento do corpo no 
período pré e pós-operatório e a imagem corporal presentes nos discursos de muIheres obesas submetidas à Cirurgia bariátrica. Além disso, o eixo dessa investigação consistiu em demonstrar as representações de corpo no cotidiano dessas mulheres, pacientes do Serviço de Controle de Hipertensão e Diabetes - SCHDO -, e inferir as relações implícitas dentro de um sistema cultural mais abrangente.

\section{MATERIAL E MÉTODOS}

\section{ASPECTOS ÉTICOS}

A pesquisa foi submetida ao Comitê de Ética da Universidade Federal de Juiz de Fora (parecer número 197/2007), em seguida, pelo Conselho de Ética da Subsecretaria de Saúde do Município de Juiz de Fora, e finalmente autorizada pela Coordenadoria da Instituição.

\section{PARTICIPANTES}

A partir da realidade do tratamento da obesidade através da Cirurgia bariátrica, no Município de Juiz de Fora, MG, a seleção da Instituição pesquisada e estudada, seguiu os seguintes critérios:

A instituição pesquisada foi o Serviço de Controle de Hipertensão e Diabetes - SCHDO - pólo de obesidade do Serviço Único de Saúde por atender os seguintes critérios de inclusão: estar localizada no Município de Juiz de Fora, MG, ter experiência no atendimento a pessoas obesas, ser uma instituição pública, haver aceitação da Secretaria Municipal de Saúde, da coordenação e dos demais funcionários em apoiar a realização do estudo e com ele colaborar.

Para a amostra, foram selecionadas, para as entrevistas, 20 mulheres, seguindo os seguintes critérios de inclusão: ter realizado a Cirurgia bariátrica há pelo menos um ano, demonstrar motivação para participar do Projeto de Pesquisa, ser mulher, pertencer ao quadro de pacientes do SCHDO.

O grupo pesquisado apresentou o seguinte perfil: idade média de 40 anos, que realizaram a cirurgia no tempo médio de 2,85 anos. A média de peso e do índice de massa corporal (IMC) no período pré-operatório era de 137, I Kg 53,26 $\mathrm{Kg} / \mathrm{m}^{2}$, respectivamente, sendo tais valores reduzidos para $79,4 \mathrm{I} \mathrm{Kg} \mathrm{e} \mathrm{30,79} \mathrm{Kg/}$ $\mathrm{m}^{2}$. Em um ano em média as entrevistadas perderam $44,88 \%$ do peso corporal total. Das entrevistadas, $65 \%$ eram casadas, $80 \%$ possuem filhos, $60 \%$ cursou até o ensino médio, 70\% fazem acompanhamento de saúde, $40 \%$ ainda possuem algum tipo de problema de saúde. Com relação à realização de atividade física não houve 
relatos para o período pré-operatório, no entanto, 45\% delas disseram realizar alguma prática após a cirurgia.

\section{INSTRUMENTOS E PROCEDIMENTOS}

Optou-se pela pesquisa qualitativa por ser "rica em dados descritivos, possui um plano aberto e flexível e focaliza a realidade de forma complexa e contextualizada" segundo Lüdke e André (1986, p. 18). A metodologia adotada Análise do conteúdo na perspectiva de Bardin (1977). Foi utilizada também análise quantitativa simples dos dados, expressa em tabelas demonstrativas da frequência absoluta e relativa das respostas, uma vez que estas não foram mutuamente excludentes, podendo para uma mesma pergunta mais de uma resposta por entrevistada.

Como instrumento, utilizou-se um roteiro de entrevista semiestruturada. O modelo de entrevista foi composto por perguntas abertas e fechadas, versando sobre os dados pessoais e a temática estudada. $\bigcirc$ instrumento foi preparado e revisado pela pesquisadora, além de ter sido submetido à avaliação de um grupo de cinco juízes doutores.

Para cada respondente, foram coletados os seguintes dados que o identificam: idade, faixa etária, tempo de cirurgia, peso pré e pós-operatório, IMC, pré e pósoperatório, estado civil, possuir ou não filhos, profissão, escolaridade, se realizam acompanhamento médico, se possuem problemas de saúde, se praticavam e/ou praticam atividade física.

Evidencia-se que duas fontes foram utilizadas para a realização da análise qualitativa do material obtido: o arquivo oral e o texto escrito. A primeira fonte, oriunda das entrevistas, guarda detalhes conseguidos com o recurso da oralidade como: entonação, ênfase, dúvida, pausas, rapidez ou lentidão nas reações, nas repetições, entre outros. O texto escrito foi obtido através da transcrição das entrevistas gravadas, das observações anotadas a cada dia e dos documentos arquivados (BARDIN, 1977, p. 31).

Para facilitar a compreensão das ideias de cada sujeito ouvido e de tornar possível a compreensão de seus depoimentos e, ainda, possibilitar, mais tarde, o exame comparativo entre os depoimentos coletados, os discursos foram organizados de acordo com uma ordem temática, definida à medida que foram sendo lidas, exaustivamente, as entrevistas.

\section{RESULTADOS}

Os dados serão apresentados na ordem que se segue: inicialmente apresentar-se-á um gráfico referente aos prejuízos e melhoras na função antes e após a 
cirurgia bariátrica, respectivamente. Em seguida a relação entre a doença, função e imagem corporal são apresentados e discutidos a partir dos discursos organizados nas seguintes categorias: categorias invalidez, dependência, funções e papéis sociais, nova relação com o corpo.

\title{
ANÁLISE E DISCUSSÃO DOS DADOS
}

De acordo com o referencial teórico, a obesidade é uma patologia multifatorial, crônica e não-transmissível. Vista sob esse aspecto, apenas o fato de emagrecer poderia hipoteticamente solucionar o problema instalado. No entanto, concorda-se com a visão de Santos (2005, p. 46) de que a "saúde e doença são estados de um mesmo processo que é composto por fatores biológicos, culturais, econômicos e sociais e não estados estanques".

Devido a isso, viver uma situação de obesidade pode exigir do indivíduo adaptar-se a um mundo que possui valores, padrões, regras e estruturas em que, muitas vezes, o excesso de peso e as comorbidades, provavelmente serão fatores limitantes.

○ corpo limitado e restrito em suas funções foi muito destacado pelas entrevistadas, situação que demonstra melhora após a cirurgia bariátrica.

A Classificação Internacional de Funcionalidade, Incapacidade e Saúde (CIF') considera a funcionalidade de um indivíduo num domínio específico:

\begin{abstract}
Uma interação ou relação complexa entre a condição de saúde e os fatores contextuais (ambientais e pessoais). Há uma interação dinâmica entre essas entidades: uma intervenção num elemento pode potencialmente modificar um ou vários outros elementos. Estas interações são específicas e nem sempre ocorrem numa relação unívoca previsível (OMS, 2003, p. 19).
\end{abstract}

Para esta pesquisa, foram consideradas como funções: atividades de vida diária (levantar da cama, abaixar, andar, calçar, ter mais agilidade e ânimo), serviço doméstico, cuidados pessoais (depilar), sentar na cadeira, estudar, trabalhar, dirigir, função sexual e função materna.

O Gráfico I, a seguir, apresenta os prejuízos das funções com a obesidade e a melhora destas após a cirurgia bariátrica:

I. A CIF faz parte da "família" de classificações internacionais desenvolvidas pela OMS. Disponível em: <http://www.who.int/classifications/en/>. Acesso em: 8 jan. 2009. 
Gráfico I. Prejuízos e melhora funcionais relacionados à obesidade relatados pelos indivíduos antes e após a Cirurgia bariátrica.

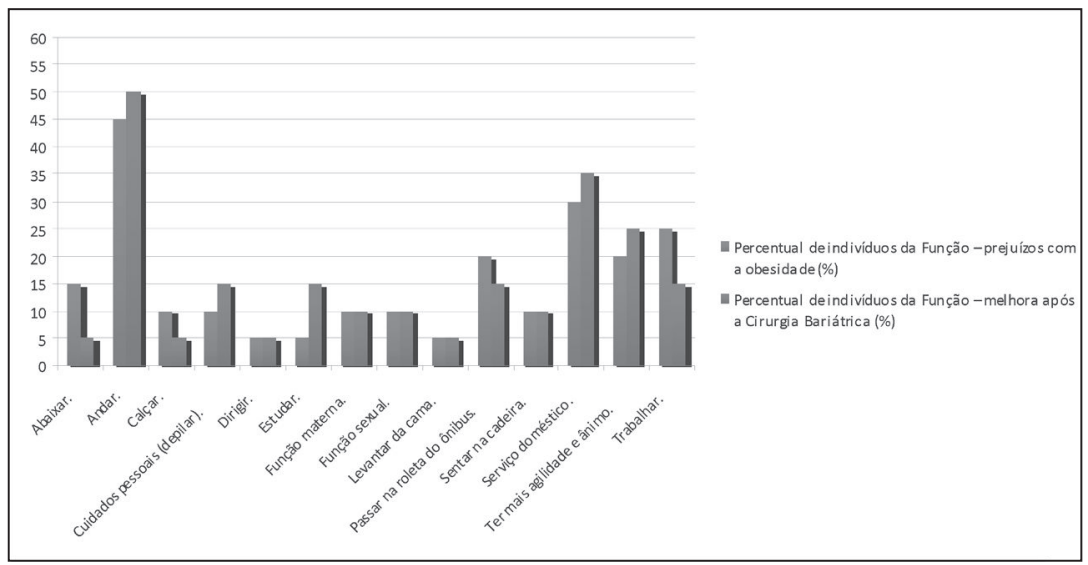

Fonte: Campo de pesquisa (maio de 2007 a dezembro de 2008).

A frequência dessas limitações nos discursos levou a uma reflexão e discussão a respeito das relações e implicações existentes entre: doença, limitações físicas provocadas por ela e Imagem Corporal.

A doença orgânica provoca sensações anormais, mudando imediatamente a imagem do corpo, do ponto de vista da figuração e do conteúdo libidinal. Estas sensações se tornam imediatamente parte da atitude e da experiência gerais do indivíduo, situando-se na base da transformação e da transposição das condensações e simbolizações [...] (SCHILDER, 1994, p. 158).

Pode-se observar tais mudanças no seguinte relato da Participante 20:

"Eu tinha a sensação de que eu estava sempre suja, eu suava debaixo do peito e tinha que passar até talco. A sensação que eu tinha é que tinha que tomar dois banhos por dia, como se a minha gordura saísse pelos poros. Era a sensação que eu tinha todos os dias".

A fala da entrevistada demonstra que "não há dúvida de que a Imagem Corporal é fundamentalmente alterada pela doença orgânica" (SCHILDER, 1994, p. 159). $\bigcirc$ estado de obesidade trazia a ela sentimento constante de incômodo com seu corpo, mudando a atenção dada à sua experiência corporal, e o nível de segurança e conforto era sentido com o próprio corpo. Essas alterações, provavelmente, implicarão uma mudança na imagem que ela possui de si.

$\bigcirc$ excesso de peso e algumas comorbidades como artrose, por exemplo, exige do sujeito adaptações no funcionamento de seu corpo em diferentes atividades, 
principalmente em situações comuns da vida como se locomover, calçar e dirigir, como relatam as participantes 2, 8 e 13, respectivamente:

"Eu não tinha habilidade de abaixar e entrar debaixo da mesa [...] tem que ajudar a calçar meia, meu menino é que amarrava meu tênis, eu não amarrava nem tênis".

"Eu tinha dificuldade para andar, para locomover mesmo. [...] se tinha que abaixar, eu ficava muito cansada... Quando eu acordava de manhã, eu sentava depois de meia hora eu levantava, eu tinha esporão no calcanhar. Adoro dirigir, eu já não tinha jeito de dirigir, fiquei uns três ou quatro anos sem dirigir, porque o meu seio, a barriga, o estômago encostavam no volante e não tinha distância para mim. Então isso para mim são grandes passos".

Pode-se fazer aqui uma analogia dos discursos apresentados com o exemplo dado por Schilder (1994, p. I55), em que, ao perder uma perna, o sujeito tende a não apenas modificar seu modelo postural do corpo em relação à perna, como também alterar algumas funções orgânicas para suprir a ausência do membro. $\bigcirc$ indivíduo altera toda sua motilidade e, como consequência, seu modelo postural. Com a obesidade, as limitações corporais, tal como o esporão calcâneo, traz ao indivíduo a necessidade de realizar as tarefas de outra forma (ou até mesmo não realizar), ou seja, de experienciar seu corpo de forma diferente, o que dá a ele uma nova imagem de si. Dessa forma, conclui-se, com base em Schilder (I 994, p. I 59), que a "modificação da função influencia imediatamente a Imagem Corporal, como se uma alteração da função fosse transmutada numa diferença estática e numa diferença de imagem". As limitações geraram nas entrevistadas, diferentes sentimentos dentre os quais os mais citados são de dependência e invalidez como mostradas nos seguintes discursos:

"Eu ir a pé a lugar nenhum eu não ia, não conseguia, eu só dependia de carro e de outra pessoa pra ir comigo, então eu me sentia assim... Muito, muito mal, porque é horrível você ser dependente de alguém ou de alguma coisa (Participante / 3)".

"Eu não queria me sentir uma inválida. Apesar de usar muleta, eu nunca me abati. Eu não tomo medicação, pra mim aquilo era um suplício, me sentir doente, viver internada. Eu queria isso. Eu queria viver, ser útil, ativa, correr atrás... (Participante 15)".

O sentimento de dependência e invalidez são fatores importantes na construção da Imagem Corporal e identidade do indivíduo nesse contexto. De acordo com Tavares (2003, p. I 0 I), sentir-se reconhecido e valorizado em sua singularidade são fatores fundamentais na integridade da identidade corporal, o que, segundo a autora, 
"é ponto de partida para desenvolvimento de uma Imagem Corporal integrada e positiva. Garante a vivência de sua impulsividade em um contexto prazeroso em que sua energia vital flui nas atividades em que realiza". A não ocupação de papéis e funções em seu contexto pode fazer com que o sujeito sinta-se desintegrado de sua identidade e de seu significado enquanto ser existencial.

O pensamento da autora é confirmado nos relatos das Participantes 17 e 20, no sentido de conquistarem novamente a independência de movimentos e poderem ocupar suas funções e papéis em seus contextos sociais, o que representa grande satisfação e importância por terem recuperado sua autonomia:

\begin{abstract}
"No meu trabalho, antes eu tinha que pedir as coisas... Na obesidade, eu nunca fui acomodada, mesmo com todo o peso, o pessoal ficava impressionado de me ver fazendo vitrine [Ela trabalha em loja]. E hoje subir em cima de um banco, para algumas pessoas, pode parecer banal, mas para mim não é".
\end{abstract}

"Eu já consigo vestir minha roupa, já consigo calçar meu sapato, umas coisas bestas que eu até chorei quando fiz as primeiras vezes [... então o que mudou foi essa sensação de me sentir mais independente. Eu consigo fazer as coisas em casa melhor, limpar minha casa..."

A incapacitação, de acordo com Benedetti (2003, p.59), exige um ajustamento. E isso dependerá do tipo de incapacitação e dos papéis ocupados pelo indivíduo antes da enfermidade, bem como da estrutura e da flexibilidade da família. A autora salienta ainda que o adoecimento crônico não incide apenas sobre o doente, mas sobre todas as suas redes de relações, sendo importante que estas sejam entendidas para que se compreenda o "significado e o re-significado da transição saúde-doençasaúde" (BENEDETTI, 2003, p. 72).

Assim, os papéis de mãe, dona de casa e de mulher, perfil das entrevistadas, confirma a afirmação da autora, na medida em que a obesidade interfere nessas funções. Ou seja, ser mãe e não poder interagir com os filhos, ser dona de casa e não realizar as tarefas correspondentes são aspectos que sobressaem nos depoimentos. Os relatos mostram como isso modificou após a perda de peso:

"Eu dou mais assistência aos meus filhos em casa, coisa que eu não fazia, entendeu? Eu ia ao mercado, não aguentava vir com uma sacolinha do mercado [...] as pessoas do mercado tinham que levar pra mim (Participante 13)".

"Muita coisa que eu não fazia na minha casa sozinha eu faço agora, não dependo de ninguém. Limpar as coisas no alto, subir e descer as escadas, limpar uma janela, isso era meu filho que fazia porque eu tinha medo de subir e cair (Participante 14)". 
Tavares (2003, p. I I 8) apresenta estudos referentes aos aspectos tangíveis e intangíveis do movimento. Aqueles se referem ao teor utilitário do movimento, já estes ao significado especial que um movimento possui para o indivíduo e que o remete a uma sensação de prazer, traduzindo a relação entre o sujeito e o próprio movimento. A autora afirma que:

Os aspectos intangíveis do movimento se referem às nossas singularidades, como as que emanam de nossos impulsos. A continência desses aspectos intangíveis em nossos movimentos cotidianos garante melhor qualidade de vida, uma vez que nossa vida é preenchida por movimentos, muito deles direcionados para o trabalho ou funções específicas (TAVARES, 2003, p. I20).

Poder voltar a trabalhar e estudar faz parte dos aspectos tangíveis e que segundo Tavares (2003, p. I 20), garante recompensa externa, como salário e relacionamento social. Mas o que existe de especial nessas funções para cada indivíduo? Ou seja, o que significa, para cada mulher entrevistada, ter o seu corpo limitado em suas funções que as impede de desempenhar alguns papéis em suas vidas? A Participante I, sobre o assunto, assim se expressa:

"Eu me escondia atrás da gordura, não queria saber de mais nada. Logo depois que eu operei, eu pude voltar a viver e procurar outras coisas para mim. Hoje eu me sinto mais ágil. Eu vou andando em tudo. Eu fico o tempo todo no hospital [local de trabalho dela] em pé e, se fosse antes, não daria".

Também houve uma entrevistada que relatou: "Voltei a trabalhar. Eu já trabalhei de motorista particular, um ano, saí. Tudo de bom aconteceu comigo depois da perda de peso" (Participante 4).

Pode-se perceber que as entrevistadas não se reportam às recompensas como o salário, por exemplo, mas sim ao quanto é gratificante para elas poderem realizar tais tarefas. Desse modo, poder ocupar um papel social e se sentir reconhecido traz o sujeito ao contato consigo, integrando-o à sua identidade.

A função sexual, o relacionamento com o companheiro, é também reportada e aqui exemplificada pelas participantes 16 e 6, que relatam melhora e maior interação com o cônjuge:

"Tenho prazer sim com meu corpo... Até em relação sexual, posições diferentes. Antes eu não tinha vontade de ter relação sexual. Antigamente eu não tinha vontade de ter. Eu achava que eu não era normal. E hoje, depois de 40 anos, eu penso: gente eu perdi muito tempo! Atrapalha o sexo, muito pesada como eu ia transar? Agora namoro que é uma beleza! Até comprei calcinha nova! (tira da bolsa e me mostra). Melhorou muito o sexo com meu marido". 
Nesse momento, o papel de mulher e esposa toma novos sentidos e prazeres na descoberta do próprio corpo e a relação com o cônjuge.

A relação com o mundo externo à sua casa, em situações em que os olhares se voltariam para ela, tais como em ônibus, cinema e teatro, já não ocorre mais como no relato da Participante I I:

"Eu ficava esperando horas e horas um ônibus vazio para poder entrar. Hoje entro no ônibus pela porta de trás, posso levar minha filha no cinema, teatro: posso levar ela. Hoje porque quando eu ia ao cinema eu tinha que sentar lá atrás porque o banco não cabia, aí tinha que sentar na pontinha. Se entrasse no ônibus, você tinha que sentar na pontinha, eu ainda brincava: eu pago passagem inteira e tenho que sentar só na metade. Hoje é normal"

As Participantes 7 e 19 também tecem considerações a esse respeito, contando a dificuldade de se adequar a cadeiras e participar de eventos:

"Eu fui ao cinema aí é que eu vi a dificuldade. Eu fui ao cinema e não tinha cadeira para mim. Aquela cadeira já ficou me sufocando. Eu já tive que pedir outra cadeira! Foi até na formatura do meu filho que eu tive que pedir outra cadeira, porque não tinha cadeira para mim, que desse confortavelmente sentada. Aí isso me incomodou, porque, assim, eu já não posso ir ao cinema, eu fiquei com aquilo na cabeça, ao cinema eu não posso, se alguém me convidar pra uma festa nesse local eu tenho que desistir porque eu não posso ir. Ou, então, eu tenho que ficar pedindo cadeira (Participante 7)".

"O que mais me incomodava era cadeira. Todo evento que a gente vai, formatura, mesmo restaurante, eu ficava com medo da cadeira quebrar... Eu ficava sempre "com um pé atrás". Em qualquer coisa que eu não conseguia, subir escada... Qualquer coisa que eu não conseguia fazer antes e hoje eu consigo eu fico feliz (Participante 19)".

Tais relatos evidenciam o quanto o padrão corporal é da menor silhueta, e ainda os espaços, tais como cinema, teatro, ônibus, entre outros, ainda não estão preparados para receberem essas pessoas, colocando-as em situações constrangedoras e, algumas vezes, excluindo-as.

Ressalta-se, também, a relação estabelecida com o corpo após a perda de peso, a experiência de possibilidades de movimento, bem como a realização de tarefas, que ficam expressas nas falas das seguintes entrevistadas: "Eu tinha medo de andar [...] o andar hoje é um prazer, porque antes era uma agonia, eu andava olhando para o chão com medo de cair" (Participante 3). E ainda:

"Hoje eu ando de bicicleta, há cinco anos eu jamais subiria numa bicicleta. Tudo que eu quiser fazer hoje eu faço. Antes nada me era possível. Uma que eu não queria que fosse, eu hoje quero, eu consigo mesmo se tiver algum obstáculo (Participante 4)". 
"Eu dou muito mais valor em andar, sair. Hoje eu consigo fazer muita coisa que antes eu não fazia. Igual hoje eu trabalhei o dia em pé, coisa que há dois anos atrás eu não conseguiria fazer (Participante 9)".

Além disso, essas mulheres relataram dificuldades em cuidar de seu corpo, como apresenta a seguinte entrevistada:

"Agora eu já consigo, mas eu achei o máximo porque eu não conseguia. Quando eu tomava banho, pra depilar era um desespero. Eu tinha que sentar no chão do banheiro, por um espelho e via aquela coisa imensa (risos) (Participante 20)".

É notável a satisfação das entrevistadas no sentido de voltarem a perceber seu corpo em movimento, realizarem atividades de seu cotidiano e poderem ter cuidados pessoais com seu corpo. Tais atividades não só lhes possibilitaram a voltar a se movimentar, como também a estarem em contato, novamente, com suas sensações internas. Reportando-se novamente a Tavares (2003, p. 102), para salientar a importância da conexão do indivíduo com suas sensações corporais, tem-se que "é o vínculo de cada movimento com nossa realidade interna que sustenta a nossa identidade durante toda a nossa vida". É necessário tornar as sensações corporais tão verdadeiras e pertinentes ao corpo quanto outros elementos, tais como o fisiológico, o cultural ou o afetivo. Assim, esse contato com o corpo, com suas sensações, dará ao sujeito a noção de quem ele foi ontem, de quem ele é hoje, e será referencial de quem ele será amanhã.

Em concordância com Tavares (2003, p. I27), Turtelli (2003, p. 66) lembra que o "movimento é imprescindível na construção da Imagem Corporal", não apenas o movimento do presente, mas também memória e experiência motora que o sujeito traz com ele. A autora ainda salienta que é através do movimento que o indivíduo passa a conhecer seu corpo e o mundo a seu redor. Assim, retomar a liberdade de se mover livremente aparece nos depoimentos, gerando prazer e trazendo ao sujeito um novo comportamento, uma nova forma de lidar com seu corpo, expresso no relato da Participante 8:

\footnotetext{
"Eu vou andar, vou dançar. Tem gente que pergunta que dança é essa, e eu falo que é qualquer uma. Eu ponho uma música lá e começo a dançar em frente ao espelho. Eu tô exercitando não tô? Dá que tem uma hora que você não pode sair ou não está a fim de sair, você está lá. Eu não me vejo mais na frente da televisão comendo. Não gosto mais dessas coisas. É muito bom nossa! É uma coisa assim... Pra quem tinha aquele peso todo e hoje se vê podendo mexer o corpo é tudo de bom!"
}

Pode-se perceber, nesse depoimento, a mudança no que tange à interação da Participante 8 com seu corpo e com o mundo. Pode-se inferir que ter autonomia, ocupar papéis e executar funções diárias, mesmo que sejam simples, devolvem ao 
corpo a sua função primária: interagir e se comunicar, contribuindo, desse modo, para a formaçã̃o da identidade.

Tavares (2003, p. 104) explica esse dinamismo, afirmando que "diferenciamonos no mundo pelas nossas percepções. $\bigcirc$ desenvolvimento de nossa identidade corporal está ligado à vivência e ao reconhecimento de nossas percepções. Isso permite a construção de um 'eu corporal' verdadeiro".

Assim, poder ter uma segunda chance de refazer a vida, livrar-se do estigma "doente", da invalidez e da dependência, bem como retomar o contato com o corpo, toma outros sentidos e significados representados pela fala da Participante I5, a seguir:

"É todo dia que eu abro o olho de manhã e vejo que estou viva, quando eu acordo, quando estou na sala de aula, quando estou no estágio, quando estou andando na rua, no meu serviço todo dia... Porque não estou mais doente, estou viva, eu consegui ludibriar a morte".

A partir desse relato, percebe-se que, muitas vezes, a recuperação das funções ora prejudicadas trouxe aos sujeitos uma nova perspectiva de vida e uma (re) descoberta de seus corpos, reavendo funções e papéis, descobrindo novas possibilidades de movimento, trazendo-os novamente a uma estreita relação com suas percepções. Verifica-se a importância disso na seguinte afirmação:

Percebemos o mundo existindo. E é reconhecendo e vivenciando plenamente nossas percepções que existimos plenamente. Porque a base do sentido do eu está no reconhecimento do corpo, e no desenvolvimento de representações mentais do corpo coerentes com nossa realidade existência (TAVARES, 2003, p. 104).

Os dados aqui encontrados sinalizam também concordantes na literatura como Almeida, Loureiro e Santos (2002, p. 289) que ao estudarem imagem corporal em mulheres obesas evidenciaram uma relação direta entre a confiança social e a imagem corporal positiva. Os autores afirmam que em se tratando de mulheres obesas a "insegurança e os sentimentos de inadequação das mesmas frente ao ambiente parecem estar associados ao seu baixo autoconceito" (ALMEIDA; LOUREIRO; SANTOS, 2002, p. 29I).

A relação estabelecida entre doença, funcionalidade e Imagem Corporal merecem atenção cautelosa, pois o impacto negativo na Imagem Corporal pode fazer com que o indivíduo perca a conexão com suas sensações e percepções internas, comprometendo a construção de sua identidade corporal.

\section{CONSIDERAÇÕES FINAIS}

Ao investigar os discursos das entrevistadas, notou-se que, durante todo o tempo, elas se referiam ao período de obesidade para explicar algo no presente, 
apesar de terem sido operadas há mais de um ano. Então, ao lançar o olhar para tal aspecto, destaca-se a influência da função na Imagem Corporal. Vale ressaltar que a Imagem Corporal é um constructo multifatorial, lábil e constituído de diversas facetas.

A cirurgia bariátrica configurou, na vida dessas mulheres, um momento marcante de intensas mudanças, uma possível oportunidade de (re) construírem-se. A obesidade mórbida implicou limitações corporais e redução em suas funções as quais foram listadas por elas: andar, abaixar, calçar, cuidados pessoais, dirigir, estudar, função materna, função sexual, levantar da cama, passar na roleta do ônibus, sentar na cadeira, fazer serviço doméstico, ter ânimo e ser ágil e trabalhar. Após a perda de peso, percebeu-se significativa melhora dessas funções. No entanto, ao voltar o olhar para a relação existente entre doença, limitação das funções e Imagem Corporal, o componente fisiológico foi agregado a outros fatores, como o que representa para essas mulheres estar doente e ter o corpo limitado.

Dessa forma, ao focar o primeiro eixo temático desta pesquisa - função e Imagem Corporal - destacou-se que, nesse grupo, a partir do momento em que se perde a função orgânica do corpo, adaptações são exigidas para realizar as atividades cotidianas e, como consequência, os papéis ocupados também são alterados. Ou seja, a mãe cuidadora passa a ser cuidada, a dona de casa passa a depender de auxílio para realizar as tarefas mais simples e, por fim, o papel de mulher e esposa se perde ou é esquecido momentaneamente. Surgem com isso, sentimentos de invalidez, dependência e inutilidade.

A recuperação de tais funções orgânicas trouxe ao grupo pesquisado a autonomia para reassumir antigos costumes e experimentar novos papéis. Essa mudança possibilitou a essas mulheres um contato maior consigo mesmas, uma vez que passaram a experimentar sentimentos de satisfação e de autoestima positiva, até então não vivenciados.

Outro ponto relevante foi a nova relação estabelecida com o corpo, a possibilidade de cuidar de si e perceber o corpo em movimento, que trouxe às entrevistadas uma conexão maior com suas sensações e percepções internas, fatores estes fundamentais para o reconhecimento das mesmas.

Acredita-se, que o indivíduo percebe o mundo existindo, e desta forma, o corpo torna-se o elo de comunicação com o mundo a seu redor, e tal relação se concretiza a partir do momento em que ele ocupa papéis e é reconhecido no contexto em que vive. Assim, pode-se afirmar que, para esse grupo, a cirurgia bariátrica devolveu ao corpo do sujeito pesquisado a sua função primária, ou seja, interagir e comunicar-se com o mundo à sua volta. As mulheres demonstraram por meio dos depoimentos, um autoconceito positivo, o que as direcionou para uma restituição de sua identidade corporal. 
Function and Body Image: an analysis from the discourse of women who underwent bariatric surgery

ABSTRACT: This article aims to encompass a study of function and body image of women who underwent bariatric surgery. Thus, were conducted a qualitative study based on the methodology of content analysis. It has been found from interviews with 20 patients from a specialized Public Health System Service from the city of Juiz de Fora / Minas Gerais, with mean age of 40 years old, who underwent surgery for 2.85 years and with mean weight loss of $74.1 \mathrm{~kg}$, the intrinsic relationship between function and body image. This were expressed by the changes after weight loss, which were emerged in the following categories: recovery of bodily functions, autonomy to resume old roles (such as perform duties like housekeeping, work or face the same relationships in different ways), and risking new experiences. So, the research group began to experience feelings of satisfaction and positive self-esteem, not so far experienced.

KEY WORDS: Obesity; bariatric surgery; body image.

\section{Función y Imagen Corporal: un análisis desde el discurso de las mujeres sometidas a la cirugía bariátrica}

RESUMEN: Este artículo incluye un estudio sobre la correlación entre la función y la imagen corporal de las mujeres que se sometieron a cirugía bariátrica. Para esto se hizo un estudio cualitativo basado en la metodología de análisis de contenido. Se ha comprobado desde las entrevistas realizadas con 20 pacientes de un servicio especializado del Sistema de Salud de la ciudad de Juiz de Fora / Minas Gerais, con edad media de 40 años y que se habían sometido a cirugía desde hace 2,85 años, con pérdida de peso de 74, I Kg., la relación intrínseca entre la función y la imagen corporal. Esto se expresa por los cambios después de la pérdida de peso, que han surgido en las siguientes categorías: recuperación de las funciones corporales, de la autonomía de reanudar viejos roles sociales (como realizar tareas como la limpieza de casa, trabajar o incluso mirar a las relaciones de diferentes maneras), además de correr el riesgo de nuevas experiencias. Así, el grupo investigado ahora experimenta sentimientos de satisfacción y autoestima positiva, hasta ahora no experimentados

PALABRAS CLAVE: Obesidad; cirugía bariátrica; función; imagen corporal.

\section{REFERÊNCIAS}

ADES, L.; KERBAUY, R. R. Obesidade: realidades e indagações. Revista de Psicologia da USP, São Paulo, v. 13, n. I, p. 197-216, 2002.

ALMEIDA, G. A. N., LOUREIRO, S. R.; SANTOS, J. E. A imagem corporal de mulheres morbidamente obesas avaliada através do desenho da figura humana. Psicologia: Reflexão e Crítica, Maringá, v. 15, n. 2, p. 283-292, 2002.

ARASAKI, C. H. et al. Cirurgia bariátrica para tratamento da obesidade. In: CLAUDINO, A. de M.; ZANELLA, M. T. (Orgs.). Guia de Transtornos Alimentares e Obesidade. São Paulo: Manole, 2005. p. 287-296. 
BARDIN, L. Análise de conteúdo. Lisboa: Edições 70, 1977.

BENEDETTI, C. De obeso a magro: a trajetória psicológica. São Paulo: Vetor, 2003.

CABRAL, M. D. Tratamento clínico na obesidade mórbida. In: GARRIDO JUNIOR, A. B. Cirurgia da obesidade. São Paulo: Atheneu, p. 35-44, 2002.

CASH, T. F. The psychology of physical appearance: aesthetics, attributes, and images. In: CASH, T. F; PRUZINSKY, T. Body Image: development, deviance and change. New York: Guilford Press, p. 51-79, 1990.

COTINHO, W. Consenso Latino-Americano de Obesidade. Arquivos Brasileiros de Endocrinologia e Metabologia, v. 43, 1999 February. Retrieved in September, 04, from < http:// scielo.bvs-psi.org.br>. Acesso em: 20 jan. 2010.

FARIAS, F. Cirurgia bariátrica: histórico. In: SILVA, R. S. da; KAWARA, N. T. Cuidados pré e pós-operatórios na cirurgia da obesidade. Porto Alegre: AGE, 2005. p. 34-45, 2005.

FERNANDES, M. H. Corpo. São Paulo: Casa do Psicólogo, 2003.

FRANCISCHI, R. P. P. de. et al Obesidade: atualização sobre sua etiologia, morbidade e tratamento. Revista de Nutrição, Campinas, v. 13, n. I, jul. 2000. Disponível em: < http://www. scielo.br>. Acesso em: set. 2008.

LÜDKE, M.; ANDRÉ, M. E. D. Pesquisa em educação: abordagens qualitativas. São Paulo: EPU, 1986.

MCARDLE, W. M.; Katch, F. I.; Katch, V. L. Fundamentos da fisiologia do exercício. 2. ed. Rio de Janeiro, RJ: Guanabara Koogan, 2000.

MOLINA JUNIOR, S.; ZANELLA, M. T. Atividade física no tratamento da obesidade. In: CLAUDINO, A. de M.; ZANELLA, M. T. Zanella (Orgs.). Guia de transtornos alimentares e obesidade. São Paulo: Manole, p. 253-258, 2005.

National Institutes Of Health Consensus Development Conference Statemente. Health Implications of Obesity. Annals of Internal Medicine, n. 103, 1985 December. p. 147- I 5 I. Disponível em: <http://consensus.nih.gov/l 985//985Obesity049html.htm>. Acesso em: jul. 2009.

SANTOS, E. M. C.; BURGOS, M. G. P. de A.; SILVA, S. A. da. Perda ponderal após a Cirurgia bariátrica de Fobi-Capella: realidade de um hospital universitário do Nordeste brasileiro. Revista Brasileira de Nutrição Clínica, Porto Alegre, v. 2 I , n. 3, p. I 88-92, 2006. Disponível em http://www.sbnpe.com.br/revistaN21-3_02.pdf. Acesso em: jan. 2010.

SCHILDER, P. A imagem do corpo: as energias construtivas da psique. Trad. Rosane Wertman. 2. ed. São Paulo: Martins Fontes, 1994.

SEGAL, A.; FANDINO, J. Bariatric surgery indications and contraindications. Revista Brasileira de Psiquiatria, São Paulo, v. 24, supl. 3, dez. 2002. Disponível em: < http://www.scielo.br/scielo. php?script=sci_arttext\&pid=S I 5 | 6-444620020007000 I 5 >. Acesso em: | 4 jul. 2008. 
SOUTO, K. E. P. Tratamento clínico da obesidade mórbida: uso de fármacos antiobesidade. In: SILVA, R. S. da; KAWARA, N. T. Cuidados pré e pós-operatórios na cirurgia da obesidade. Porto Alegre: AGE, 2005. p. 46-49

TAVARES, M. da C. G. C. F. Imagem Corporal: conceito e desenvolvimento. Barueri, SP: Manole, 2003.

TURTELLI, L. S. Relações entre imagem corporal e qualidades de movimento: uma reflexão a partir de uma pesquisa bibliográfica. 2003, 332 f. Dissertação (Mestrado em Educação Física) Curso de Educação Física, Faculdade de Educação Física, Universidade Estadual de Campinas. Campinas, 2003.

WAjCHENBERG, B. L. (Org.). Tratado de Endocrinologia Clínica. São Paulo: Roca, 1992.

WHO. World Health Organization. Diet, physical activity and health. The world health report 200 I. Mental health: new understanding, new hope. World Health Organization, 2007. Retrieved in July, 10, from <http://www.who.int/gb/>. Acesso em: 6 jul. 2009.

WHO. World Health Organization. Obesity: preventing and managing the global epidemic, 1998. Report of WHO Consultation on Obesity. Geneva: World Health Organization.

WHO. World Health Organization. Obesity, 2009. Disponível em: <http://www.who.int/ topics/obesity/en/>. Acesso em: 19 jun. 2009.

ZANELLA, M. T. Obesidade e risco cardiovascular. In: CLAUDINO, A. de M.; ZANELLA, M. T. (Orgs.). Guia de transtornos alimentares e obesidade. São Paulo: Manole, 2005. p. 219-226.

ZANELLA, M. T. Tratamento. In: CLAUDINO, A. de M.; ZANELLA, M. T. (Orgs.). Guia de Transtornos Alimentares e Obesidade. São Paulo: Manole, 2005. p. 235-242.

Recebido: 03.02.2010

Aprovado: 17.07.2010

Endereço para correspondência:

Marcela Rodrigues de Castro Rua Severiano sarmento, 488/20 I

Bairro Passos, Juiz de Fora-MG,

CEP: 36026420 